\title{
Prevalence and associated factors of contraceptive discontinuation and switching among Bangladeshi married women of reproductive age
}

This article was published in the following Dove Press journal:

Open Access Journal of Contraception

29 January 2015

Number of times this article has been viewed

\author{
Rashidul Alam Mahumud' \\ Md Golam Hossain ${ }^{2}$ \\ Abdur Razzaque Sarker \\ Md Nurul Islam² \\ Md Ripter Hossain ${ }^{2}$ \\ Aik Saw ${ }^{3}$ \\ Jahangir AM Khan ${ }^{1,4}$ \\ 'Health Economics and Financing \\ Research Group, Center for Equity \\ and Health Systems, International \\ Centre for Diarrhoeal Disease \\ Research, Bangladesh, Dhaka, \\ Bangladesh; ${ }^{2}$ Department of \\ Statistics, University of Rajshahi, \\ Rajshahi, Bangladesh; ${ }^{3}$ Department \\ of Orthopaedic Surgery, National \\ Orthopaedic Centre of Excellence \\ for Research and Learning, Faculty \\ of Medicine, University of Malaya, \\ Kuala Lumpur, Malaysia; ${ }^{4}$ Adjunct \\ Faculty, Health Economics Unit, \\ Department of Learning, Informatics, \\ Management and Ethics, Karolinska \\ Institutet, Stockholm, Sweden
}

Introduction: Contraceptive discontinuation is a worldwide incident that may be connected with low incentive to avoid pregnancy. Contraceptive discontinuation highly contributes to unplanned pregnancy and unwanted births.

Objectives: The objective of this study was to observe the prevalence of discontinuation and switching of contraceptive methods among Bangladeshi married women. In addition, the sociodemographic factors associated with contraceptive discontinuation and switching were assessed.

Methods: Secondary cross-sectional data was used in this study. A total of 16,273 married Bangladeshi women of reproductive age (15-49 years) were considered in the present study, from the Bangladesh Demographic and Health Survey, 2011. Logistic regression models were used to determine the relationships between key sociodemographic factors and user status.

Results: The prevalence of discontinuation and switching of contraceptive method among women were $38.4 \%$ and $15.4 \%$, respectively. The logistic regression model demonstrated that women in early reproductive years (25-29 years and 30-34 years) significantly more often (odds ratio $[\mathrm{OR}]=0.84$ and 0.71 , respectively) discontinued use of contraceptives. Significantly higher rates of discontinuation were pronounced among women who used the pill $(\mathrm{OR}=0.72)$ and injectable contraception users $(\mathrm{OR}=0.60)$, had small family size $(\mathrm{OR}=0.49)$, lived in a rural community $(\mathrm{OR}=1.65)$, and who were less educated $(\mathrm{OR}=1.55)$.

Conclusion: Contraceptive discontinuation may reflect an association among less education, currently married, and smaller family size. Awareness of contraceptive methods can decrease the burden of unplanned pregnancies and thus progresses the family planning program.

Keywords: prevalence, contraceptive discontinuation, switching, BDHS, odds ratio, logistic regression

\section{Background}

Contraception is an effective form of family planning, and over three-quarters of women in developing countries have used a form of contraception during their lifetime. ${ }^{1}$ Contraceptive discontinuation contributes substantially to unplanned pregnancies, unwanted births, and termination of pregnancies. Every year, about one-third of the 182 million pregnancies occurring worldwide are unplanned. ${ }^{2}$ Discontinuation of effective methods of contraception is a universal problem, though rates vary widely by population and country. ${ }^{1}$ There are many possible reasons for contraceptive discontinuation, including contraception failure, actual or perceived problems with the contraception method, lack of information, or religious reasons. Low incentive to avoid pregnancy may also be an important factor in some communities. ${ }^{3}$
Correspondence: Rashidul Alam Mahumud Health Economics and Financing Research Group, Center for Equity and Health Systems, International Centre for Diarrhoeal Disease Research, Bangladesh, 68, Shaheed Tajuddin Ahmed Sarani, Mohakhali, Dhaka, Bangladesh

Tel +8801719105336

Fax +88028811568

Email rashidul.alam@icddrb.org 
In the modern world, the medical and health status of woman and children has improved significantly, and many children survive to adulthood. At the same time, more women are able to freely decide on when and how many children they wish to have. As a result, there has been a gradual decline in the global fertility rate. ${ }^{4}$ In Bangladesh, the general standard of living has improved over the last few years, due to good performance in the national economy and better access to education for the general population. However, the rate of population growth is too high, ${ }^{5}$ and this may undermine the social and economic improvements in the near future. Family planning is one of the few strategies that can effectively modify the rate of population growth so that the increase in population is sustainable by the economic performance of the country.

A recent study reported that three in five married women in Bangladesh used some form of contraception; about $36 \%$ of these users discontinued the contraceptive method within 12 months, and $52 \%$ of the discontinued contraceptives were considered modern method. ${ }^{6}$ A relatively recent (2009) study by Sarker reported that in Bangladesh, $32.80 \%$ of pregnancies were unplanned; the author concluded that this is an important factor for the rapid growth of the population of this country. ${ }^{7}$ Despite extensive efforts by the government and nongovernmental organizations (NGOs) to promote and provide free facilities for contraception to married women, rapid population growth has persisted.

Contraception discontinuation is one of the known contributing factors for increasing number of unplanned pregnancies. ${ }^{6,8-10}$ A study in 2009 among ten developing counties reported that Bangladesh has the second highest rate $(49 \%)$ of contraceptive discontinuation among these countries, after the Dominican Republic (63\%-65\%). ${ }^{1}$ In a previous study by Trussell in the United States, medical costs associated with unplanned pregnancies were as high as USD 5.0 billion per year; regular contraceptive use might have prevented 12.0 million pregnancies every year, and this would have saved USD 19.3 billion for the nation. ${ }^{9}$ Another study based on Demographic and Health Survey (DHS) data from 18 countries reported that 20\%-50\% of modern reversible contraceptive method users discontinued use within the first 12 months. ${ }^{9,10}$ Another study of DHS data from eight countries reported a 12-month discontinuation rate of $18 \%-49 \% .{ }^{1}$ A more recent study on use of the oral contraceptive method in 19 countries showed that $35 \%$ of women discontinued its use within 3 months. ${ }^{11}$

A previous study demonstrated that education, area of residence, and household economics status are the most important factors associated with contraceptive discontinuation. ${ }^{12}$ However, urban women and women with higher levels of education and socioeconomic status are more likely to switch than stop after discontinuing a method, whereas older age is related to a decreased likelihood of switching. ${ }^{12,13}$ Contraceptive discontinuation may indicate a missed opportunity to promote and sustain contraceptive use, and therefore it can be used to measure the effectiveness of family planning service. ${ }^{14,15}$ High-quality family planning service would provide information on a range of contraceptive methods and offer more comprehensive counseling. This would increase the likelihood that a woman will switch to safer or more effective contraceptive method rather than discontinue its use altogether. ${ }^{15}$

We designed this study to investigate the high rate of contraceptive discontinuation in Bangladesh. We hoped to identify factors associated with the discontinuation of common contraception methods in this country, to support relevant authorities in planning new strategies to improve the situation.

\section{Methods \\ Data}

The present study was based on a secondary analysis of Bangladesh Demographic and Health Survey (BDHS) 2011 data. The BDHS was a national-level household-based survey that utilized a stratified, two-stage cluster design: the first stage involved selecting samples from a master sampling frame constructed from enumeration areas in the Bangladesh Population and Housing Census 2011, provided by the Bangladesh Bureau of Statistics; the second stage involved the systematic sampling of the households listed from each cluster, to ensure adequate numbers of completed individual interviews were obtained. The survey collected data through questionnaire-based interviews, based on the MEASURE DHS program model. ${ }^{6}$ Data used in this analysis was restricted to responses from women who had ever used a method of contraception in the 5 years preceding the survey, and where complete contraceptive histories were provided. In the 2011 BDHS, all women aged 12-49 years in the selected households were administered a questionnaire between July 8, 2011 and December 27, 2011, to collect information covering the 5 years preceding the survey, on respondent's socioeconomic, demographic, and anthropometric information, reproductive history, living conditions, knowledge and use of contraception, and other health topics. ${ }^{6}$ Trained interviewers interviewed a total of 17,842 with ever-married women aged 12-49 years. The reproductive-aged women (aged 15-49 years) were considered in the current study. 
The data set was checked for outliers, using statistical techniques, because abnormal data can affect the interpretation of results. ${ }^{16,17}$ Excluded from this study were 1,048 women who had indicated that they were pregnant at the time of the survey and 79 women who were aged $\leq 14$ years old; thus, the data set was reduced from 17,842 to 16,273 for the analysis in the present study. This analysis focused on the data from episode-based for both modern and traditional family planning options available in Bangladesh.

\section{Data analysis}

Respondents were classified into two groups: the "discontinued use" group (if they had used a contraceptive method in the past 12 months but were not doing so at the time of the survey) and the "contraceptive switched" group (if their current method differed from their previous method used). An inferential statistical test was used to assess differences between the two groups of married women, by contraceptive discontinuation or switching status. Logistic regression was used to investigate associations between user status and factors that had been previously identified as significantly associated in bivariate analysis, in the literature. The models controlled for married woman's 5-years age group were analyzed according to the reproductive period (15-49), number of living children (parity), fertility preferences, history of a terminated pregnancy, place of residence, religion, highest education grade completed, and wealth index. Assessment of the strength of these factors as predictors was done using odds ratios (OR) and their 95\% confidence intervals (CI) for comparisons of their effect on discontinued use and switching. Statistical analysis of the data was performed using STATA 12 (StataCorp LP, College Station, TX, USA).

\section{Results \\ Background characteristics}

Contraceptive discontinuation was identified among 6,244 $(38.4 \%)$ of the women in the sample selected (Table 1). A majority of these women had a preference for more children (74.8\%), had completed secondary education (34\%), and lived in rural areas $(66.8 \%)$. More than half of women who discontinued had 1 to 2 living children. Twenty percent of these women indicated a history of a terminated pregnancy. Muslim (89.9\%) women registered higher rate of contraceptive discontinuation compared with their women counterparts of other religions.

Among the sample of current users studied, 2,506 (15.4\%) women had switched from their previous method at the time of the survey (Table 1). Compared with the discontinued group, more than $30 \%$ women who had switched contraceptive methods were aged 20-24 years, followed by $24.5 \%$ in the age range 25-29 years; $46.3 \%$ were secondary-level educated; $59.1 \%$ had 1-2 children; and $79.9 \%$ of women had a pregnancy termination (Table 1). This group were predominantly "spacers" who wanted to have another child (73.5\%). Approximately $61.81 \%$ of women who were case response the contraceptive discontinued by former pill users, followed by $18 \%$ of injectable contraception users (Table 3 ). On the contrary, $66.32 \%$ of women who were switched by pill followed by injection users $(17.43 \%)$.

\section{Multivariate analysis}

The logistic regression model suggested that place of residence, age, parity, fertility preference, and wealth quintile were shown to be the significant factors for contraceptive discontinuation (Table 2). The analysis suggested that respondents from the rural community were about two times more likely to discontinue use relative to respondents from the urban community. However, respondents aged 25-34 years old were more likely to have discontinued compared with respondents aged less than 20 years. The analysis also suggested that respondents with no formal education or illiterate were more than 1.5 times more likely to have discontinued use relative to those who had completed higher education (Table 2). Women who did not intend to have other children were less likely to have discontinued contraceptive use. Previous use of the pill, intrauterine device (IUD), and injection were found to be associated with approximately less than one time the discontinuation which was even higher than that recorded by other acting methods (Table 4). Conversely, education, age, parity, fertility preference, place of residence, and wealth quintile were also shown to be the significant predictors for switching of contraceptive method. The analysis suggested that respondents aged 25-34 years old were more likely to have switched compared with respondents aged less than 20 years. Respondents who were secondary level-educated were more likely to have switched contraceptive methods relative to those who had less education. As for fertility preference, respondents who did not intend to have children were more likely to have switched contraceptive methods compared with those who wanted another child. However, the respondents who lived in a rural community were more than 1.6 times more likely to have switched the method compared with those living in an urban community (Table 2). The respondents of pill, IUD, and injection users were more likely to have switched the contraceptive method as compared with those using other methods (Table 4). 
Table I Distribution of selected sociodemographic characteristics for contraceptive users, by user type

\begin{tabular}{|c|c|c|c|}
\hline \multirow[t]{3}{*}{ Characteristics } & \multicolumn{3}{|l|}{ Type of user } \\
\hline & $\begin{array}{l}\text { Discontinued } \\
\text { (no method) }\end{array}$ & $\begin{array}{l}\text { Switched } \\
\text { (different method) }\end{array}$ & $\begin{array}{l}\text { Currently using } \\
\text { any method }\end{array}$ \\
\hline & $\%(95 \% \mathrm{Cl})$ & $\%(95 \% \mathrm{Cl})$ & $\%(95 \% \mathrm{Cl})$ \\
\hline Age, years (mean $\pm S D)$ & $32.7 \pm 10.2$ & $26.1 \pm 7.1$ & $30.5 \pm 8.4$ \\
\hline \multicolumn{4}{|l|}{ Age group $* / * *$} \\
\hline $15-19$ & $10.4(9.7-1 \mid .2)$ & $18.3(16.8-19.9)$ & $9.1(8.5-9.7)$ \\
\hline $20-24$ & $17.5(16.6-18.4)$ & $29.7(27.8-31.5)$ & $19.0(\mid 8.2-19.7)$ \\
\hline $25-29$ & $15.4(\mid 4.6-16.3)$ & $24.5(22.7-26.2)$ & $21.1(20.3-21.9)$ \\
\hline $30-34$ & $11.9(\mid 1.1-12.7)$ & $13.8(\mid 2.5-15.2)$ & $17.8(17.0-18.5)$ \\
\hline $35-39$ & II.5 (I0.7-12.2) & $8.1(7.0-9.2)$ & $14.9(\mid 4.2-15.6)$ \\
\hline $40-44$ & $14.6(\mid 3.8-15.5)$ & $4.0(3.2-4.8)$ & $11.9(11.3-12.5)$ \\
\hline $45-49$ & I8.6 (I7.6-19.6) & $1.6(1 . I-2.0)$ & $6.3(5.8-6.7)$ \\
\hline \multicolumn{4}{|l|}{ Education*/** } \\
\hline None & $30.7(29.5-31.8)$ & $15.9(14.4-17.4)$ & $24.6(23.8-25.5)$ \\
\hline Primary & $28.9(27.8-30.0)$ & $29.2(27.4-31.1)$ & $30.4(29.5-31.3)$ \\
\hline Secondary & $34.1(32.9-35.3)$ & $46.3(44.3-48.3)$ & $36.0(35.0-36.9)$ \\
\hline Higher & $6.4(5.8-7.0)$ & $8.6(7.4-9.7)$ & $9.0(8.4-9.6)$ \\
\hline \multicolumn{4}{|c|}{ Number of living children (parity)*/** } \\
\hline None & $20.8(|9.8-2| .8)$ & $17.7(16.1-19.2)$ & $6.5(6.0-7.0)$ \\
\hline 1 to 2 & $55.2(54.0-56.5)$ & $59.1(57.1-61.1)$ & $63.6(62.7-64.6)$ \\
\hline 3 to 4 & $20.1(19.1-2||)$. & $20.2(|8.6-2| .8)$ & $26.2(25.4-27.1)$ \\
\hline 5 and more & $3.9(3.4-4.4)$ & $3.0(2.3-3.7)$ & $3.7(3.3-4.0)$ \\
\hline \multicolumn{4}{|l|}{ Fertility preference $* * * *$} \\
\hline Wanted another child & $74.8(72.8-76.7)$ & $73.5(71.1-75.9)$ & $56.9(55.5-58.2)$ \\
\hline Undecided & I3.I (| |.6-|4.6) & $14.3(|2.4-16|)$. & $14.3(|3.4-| 5.3)$ \\
\hline Wants no more & $12.2(10.7-13.6)$ & $12.2(10.5-14.0)$ & $10.8(9.9-11.6)$ \\
\hline Sterilized (husband/partner) & 0 & 0 & $18.0(17.0-19.1)$ \\
\hline \multicolumn{4}{|c|}{ History of terminated pregnancy** } \\
\hline No & $78.2(77.2-79.2)$ & $79.9(78.2-81.5)$ & $78.2(77.4-79.0)$ \\
\hline Yes & $21.8(20.8-22.8)$ & $20.1(|8.5-2| .8)$ & $21.8(21.0-22.6)$ \\
\hline \multicolumn{4}{|l|}{ Place of residence $* / * *$} \\
\hline Urban & $33.2(32.0-34.3)$ & $30.1(28.2-31.9)$ & $36.3(35.3-37.2)$ \\
\hline Rural & $66.8(65.7-68.0)$ & $69.9(68.1-71.8)$ & $63.7(62.8-64.7)$ \\
\hline \multicolumn{4}{|l|}{ Religion*/** } \\
\hline Islam & $89.9(89.1-90.6)$ & $91.0(89.9-92.2)$ & $87.8(87.1-88.4)$ \\
\hline Hinduism & $9.7(9.0-10.5)$ & $8.7(7.6-9.8)$ & $11.7(11.1-12.3)$ \\
\hline Buddhism & $0.2(0.1-0.3)$ & $0.1(0.0-0.3)$ & $0.2(0.1-0.3)$ \\
\hline Christian & $0.2(0.1-0.3)$ & $0.2(0.0-0.3)$ & $0.3(0.2-0.4)$ \\
\hline \multicolumn{4}{|l|}{ Wealth index** } \\
\hline Poorest $20 \%$ & $17.9(\mid 6.9-18.8)$ & $17.9(16.4-19.5)$ & $16.9(\mid 6.2-17.6)$ \\
\hline Poorer & $17.5(\mid 6.5-18.4)$ & $17.0(15.5-18.5)$ & $19.0(18.2-19.8)$ \\
\hline Middle & $19.0(18.0-19.9)$ & $20.6(19.0-22.2)$ & $19.4(18.6-20.2)$ \\
\hline Richer & $21.9(20.8-22.9)$ & $22.2(20.6-23.9)$ & $21.0(20.2-21.8)$ \\
\hline Richest $20 \%$ & $23.9(22.8-24.9)$ & $22.2(20.5-23.9)$ & $23.7(20.2-21.8)$ \\
\hline Total observations (N) & $6,244(38.4 \%)$ & $2,506(15.4 \%)$ & $7,523(46.2 \%)$ \\
\hline
\end{tabular}

Notes: $* P<0.05$ among women discontinuing and those who did not; $* * P<0.05$ among women switching and those who did not.

Abbreviations: $\mathrm{Cl}$, confidence interval; SD, standard deviation.

\section{Reasons for contraceptive discontinuation}

The most common reasons given for discontinuing contraceptive method, regardless of the method currently in use, were desire to conceive, unexpected conception, and side effect or health concern. About one-third (32.87\%) of women stopped practicing contraception because they wanted to become pregnant, while about one-quarter $(26.69 \%)$ were concerned about the side effects (this was especially important for those using the injection method, among whom $50.21 \%$ of the discontinuation was attributed to concern of side effects) (Figure 1).

\section{Discussion}

This study examined contraceptive discontinuation and switching of methods in a sample population consisting of 
Table 2 Factor association for discontinued contraceptive use and switching, by selected sociodemographic characteristics

\begin{tabular}{|c|c|c|}
\hline $\begin{array}{l}\text { Background } \\
\text { characteristics }\end{array}$ & $\begin{array}{l}\text { Discontinuation } \\
\text { Adjusted OR } \\
(95 \% \mathrm{CI})\end{array}$ & $\begin{array}{l}\text { Switching } \\
\text { Adjusted OR } \\
(95 \% \mathrm{CI})\end{array}$ \\
\hline \multicolumn{3}{|l|}{ Age group } \\
\hline \multicolumn{3}{|l|}{$15-19$ (ref) } \\
\hline $20-24$ & $0.96(0.81-1.13)$ & $0.87(0.72-1.04)$ \\
\hline $25-29$ & $0.84 * *(0.69-1.01)$ & $0.70 *(0.57-0.860)$ \\
\hline $30-34$ & $0.7 \mid * * *(0.56-0.89)$ & $0.49 * *(0.38-0.64)$ \\
\hline $35-39$ & $0.64(0.47-0.86)$ & $0.37(0.26-0.530)$ \\
\hline $40-44$ & $0.56(0.37-0.85)$ & $0.25(0.14-0.43)$ \\
\hline $45-49$ & $2.03(0.98-4.23)$ & $0.19(0.06-0.65)$ \\
\hline \multicolumn{3}{|l|}{ Education } \\
\hline None & $1.55^{* *}(1.19-2.03)$ & $1.19(0.88-1.62)$ \\
\hline Primary & $1.25(0.98-1.60)$ & $1.10(0.83-1.45)$ \\
\hline Secondary & $1.23(0.98-1.54)$ & $1.12 *(0.86-1.45)$ \\
\hline \multicolumn{3}{|l|}{ Higher (ref) } \\
\hline \multicolumn{3}{|c|}{ Number of living children (parity) } \\
\hline \multicolumn{3}{|l|}{ None (ref) } \\
\hline I to 2 & $0.49 * *(0.25-0.61)$ & $0.65 *(0.40-1.06)$ \\
\hline 3 to 4 & $0.47(0.30-0.76)$ & $0.86(0.5 \mathrm{I}-1.45)$ \\
\hline 5 and more & $0.35(0.34-0.98)$ & $1.06(0.58-1.93)$ \\
\hline \multicolumn{3}{|l|}{ Fertility preference } \\
\hline \multicolumn{3}{|l|}{ Wanted another } \\
\hline Undecided & $0.66(0.57-0.77)$ & $0.75^{* * *}(0.63-0.89)$ \\
\hline $\begin{array}{l}\text { Wants no more } \\
\text { Sterilized } \\
\text { (husband/partner) }\end{array}$ & $0.59 * *(0.55-0.86)$ & $1.02(0.82-1.26)$ \\
\hline \multicolumn{3}{|c|}{ History of terminated pregnancy } \\
\hline \multicolumn{3}{|l|}{ No (ref) } \\
\hline Yes & $0.93(0.8 \mathrm{I}-1.07)$ & $0.95(0.80-1.12)$ \\
\hline \multicolumn{3}{|l|}{ Place of residence } \\
\hline \multicolumn{3}{|l|}{ Urban (ref) } \\
\hline Rural & I.65** (I.44-I.89) & $1.56 * * *(1.33-1.82)$ \\
\hline \multicolumn{3}{|l|}{ Religion } \\
\hline Islam & $1.98(0.42-9.35)$ & $1.06(0.22-5.04)$ \\
\hline Hinduism & $1.47(0.3 \mid-7.01)$ & $0.91(0.19-4.38)$ \\
\hline Buddhism & $2.87(0.4 I-20.03)$ & $0.75(0.09-6.69)$ \\
\hline \multicolumn{3}{|l|}{ Christian (ref) } \\
\hline \multicolumn{3}{|l|}{ Wealth index } \\
\hline Poorest $20 \%$ & $0.92 *(0.74-1.13)$ & $1.02(0.80-1.29)$ \\
\hline Poorer & $0.72(0.58-0.88)$ & $0.82(0.65-1.04)$ \\
\hline Middle & $0.91(0.75-1.10)$ & $1.01(0.8 \mathrm{I}-1.26)$ \\
\hline Richer & $1.04(0.87-1.25)$ & $1.06(0.86-1.30)$ \\
\hline Richest $20 \%$ (ref) & & \\
\hline
\end{tabular}

Notes: $* P<0.10 ; * * P<0.05 ; * * * P<0.01$.

Abbreviations: $\mathrm{Cl}$, confidence interval; $\mathrm{OR}$, odds ratio; ref, reference.

married women in the reproductive age group, in Bangladesh. Counseling on contraceptives usually focuses on disseminating information on family planning and providing a range of contraceptive methods. Initiation of a contraceptive method has been linked to a lower risk of unplanned pregnancy. ${ }^{3}$

When examining the results, we noted that the pill, injection, and traditional methods were associated with
Table 3 Distribution of contraceptive current use, discontinuation, and switching of respondents by method used*

\begin{tabular}{|c|c|c|c|}
\hline \multirow{4}{*}{$\begin{array}{l}\text { Contraceptive } \\
\text { method used }\end{array}$} & \multicolumn{3}{|c|}{ Current use status } \\
\hline & \multirow{3}{*}{$\begin{array}{l}\begin{array}{l}\text { Discontinued } * * \\
\text { (no method) }\end{array} \\
\%\end{array}$} & \multirow{3}{*}{$\begin{array}{l}\text { Switched** } \\
\text { (different } \\
\text { method) } \\
\%\end{array}$} & \multirow{3}{*}{$\begin{array}{l}\text { Currently } \\
\text { using** } \\
\text { (same method) } \\
\%\end{array}$} \\
\hline & & & \\
\hline & & & \\
\hline Pill & 61.81 & 66.32 & 57.79 \\
\hline IUD & 0.76 & 0.46 & I.I \\
\hline Injection & 17.75 & 17.43 & 19.97 \\
\hline Condom & 7.79 & 7.47 & 9.83 \\
\hline Periodic & 9.08 & 6.09 & 7.53 \\
\hline \multicolumn{4}{|l|}{ abstinence } \\
\hline Withdrawal & 1.69 & 1.51 & 2.19 \\
\hline Norplant & 0.72 & 0.39 & 1.31 \\
\hline Other*** & 0.40 & 0.33 & 0.22 \\
\hline Total responses & 7,801 & 4,347 & 7,771 \\
\hline Total cases & 6,244 & 2,506 & 7,523 \\
\hline
\end{tabular}

Notes: *Multiple responses considered; **case-wise percentage considered; ***other contraceptive methods included sterilization (husband/partner), and existing other modern and traditional contraceptive methods.

Abbreviation: IUD, intrauterine device.

high rates of discontinuation. Ramstrom et al reported that concern about potential side effects was the major reason for discontinuation of pill and injectable form of contraception. ${ }^{19}$ Many may not have had the proper information and were not aware of other available methods of modern contraception. Moreover, contraceptive methods with lower rate of discontinuation like IUD based on experience from other developing nations were not popular in Bangladesh. ${ }^{14}$

Younger women had higher rate of contraceptive discontinuation of any method, especially those with no children or fewer than three children. With increasing age and increasing number of children in the family, economic concerns became more important and the rate of contraceptive discontinuation reduced. This can explain the lower rate

Table 4 Odds ratio of discontinuation and switching, by contraceptive method used

\begin{tabular}{|c|c|c|}
\hline $\begin{array}{l}\text { Contraceptive } \\
\text { method used }\end{array}$ & $\begin{array}{l}\text { Discontinued } \\
\text { Odds ratio } \\
(95 \% \mathrm{Cl})\end{array}$ & $\begin{array}{l}\text { Switched } \\
\text { Odds ratio } \\
(95 \% \mathrm{Cl})\end{array}$ \\
\hline Pill & $0.72 *(0.28-1.82)$ & $0.82 * *(0.29-2.30)$ \\
\hline IUD & $0.47^{* *}(0.16-1.36)$ & $0.29 *(0.08-1.05)$ \\
\hline Injection & 0.60 ** $(0.23-1.52)$ & $0.63 * * *(0.22-1.77)$ \\
\hline Condom & $0.53(0.21-1.36)$ & $0.55(0.19-1.58)$ \\
\hline Periodic abstinence & $0.8 \mathrm{I}(0.3 \mathrm{I}-2.08)$ & $0.50(0.17-1.44)$ \\
\hline Withdraw & 0.5 I (0.19-I.39) & $0.49(0.16-1.52)$ \\
\hline Norplant & $0.37(0.13-1.07)$ & $0.21(0.06-0.80)$ \\
\hline Others (ref) & & \\
\hline
\end{tabular}

Notes: $* p<0.10 ; * * p<0.05 ; * * * p<0.01$.

Abbreviations: $\mathrm{Cl}$, confidence interval; IUD, intrauterine device; ref, reference. 

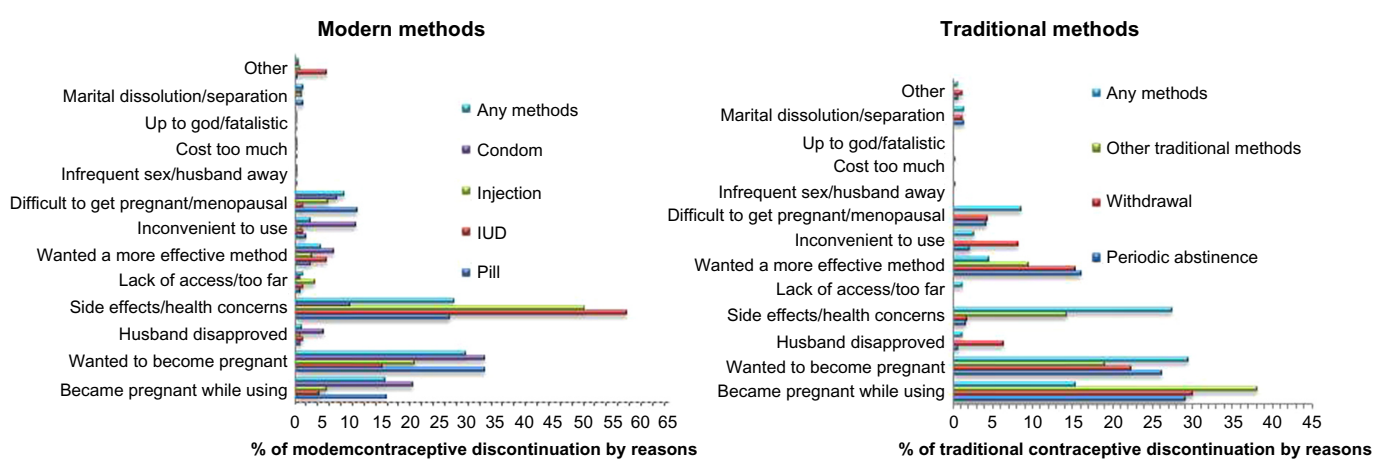

Figure I Reasons for contraceptive discontinuation by reproductive-aged married women in Bangladesh.

Abbreviation: IUD, intrauterine device.

of contraceptive discontinuation among older women in the population. The main concern is that our findings showed that contraceptive discontinuation rates among poorer, lesseducated women from rural areas were higher than among their better-educated counterparts from the rural areas. Since this is associated with unexpected pregnancies, the increasing number of children will create additional burden to the already limited financial resources of the family. For the same reasons, more women may adopt the less effective traditional methods of contraception. This may eventually create a vicious cycle that leads to poorly controlled increase in the population.

Contraceptive discontinuation is closely related to the fertility rate of a population and can reflect the effectiveness of family planning programs. The rapidly increasing population of Bangladesh in recent years corresponds to the high rate of contraceptive discontinuation in the country. Based on our findings, specific measures to disseminate information on family planning and provide effective options of contraception should be targeted at young married women from poor families in the rural areas. Providing better opportunities for general education and employment opportunities may also reduce the rate of contraceptive discontinuation indirectly, by improving the economic background of these women and their families. Contraceptive methods that are associated with lower rate of discontinuation, like IUDs, may be another solution, although these may not be readily acceptable to women from conservative cultural backgrounds.

\section{Study limitations}

There are a few limitations of this study. The sample population may not reflect the actual constitution of the country, despite the fact that representations from various geographical regions were included. It also excluded unmarried and pregnant women who might have been sexually active or practicing modern or traditional methods of contraception.
We were not able to obtain adequate information on termination of pregnancy for analysis since this practice is not culturally acceptable.

\section{Acknowledgments}

The International Centre for Diarrhoeal Disease Research of Bangladesh is thankful to the Governments of Australia, Bangladesh, Canada, Sweden, and the UK for providing core/ unrestricted support. The authors would also like to thank the MEASURE DHS program for providing access to the data used in the study.

\section{Disclosure}

The authors report no conflicts of interest in this work.

\section{References}

1. Bradley SEK, Schwandt HM, Khan S; ICF Macro. Levels, Trends, and Reasons for Contraceptive Discontinuation [DHS Analytical Studies]. Calverton, MD: ICF Macro; 2009.

2. Blumenthal PD, Voedisch A, Gemzell-Danielsson K. Strategies to prevent unintended pregnancy: increasing use of long-acting reversible contraception. Hum Reprod Update. 2011;17(1):121-137.

3. Barden-O'Fallon J, Speizer I. What differentiates method stoppers from switchers? Contraceptive discontinuation and switching among Honduran women. Int Perspect Sex Reprod Health. 2011;37(1):16-23.

4. Population Division. Demographic determinants of population ageing. In: World Population Ageing 1950-2050. New York, NY: Department of Economic and Social Affairs, United Nations; 2001:5-9. Available from: http://www.un.org/esa/population/publications/worldageing19502050/ pdf/8chapteri.pdf. Accessed December 12, 2014.

5. Population Division. Accelerating Achievement of the MDGs by Lowering Fertility: Overcoming the Challenges of High Population Growth in the Least Developed Countries [Population Facts]. New York, NY: Department of Economic Social Affairs, United Nations; 2010.

6. National Institute of Population Research and Training; Mitra and Associates; MEASURE DHIS. Bangladesh Demographic and Health Survey 2011. Calverton, MD: ICF International; 2012.

7. Sarkar P. Unintended pregnancies in Bangladesh: levels and correlates. Journal of Modern Mathematics and Statistics. 2009;3(4):78-81.

8. Ersek JL, Brunner Huber LR, Thompson ME, Warren-Findlow J. Satisfaction and discontinuation of contraception by contraceptive method among university women. Matern Child Health J. 2011;15(4): $497-506$. 
9. Trussell J. The cost of unintended pregnancy in the United States. Contraception. 2007;75(3):168-170.

10. Vadnais D, Kols A, Abderrahim N; ORC Macro. Women's Lives and Experiences: Changes in the Past Ten Years. Calverton, MD: ORC Macro; 2006.

11. Ali MM, Cleland J. Oral contraceptive discontinuation and its aftermath in 19 developing countries. Contraception. 2010;81(1):22-29.

12. Curtis SL, Blanc AK. Determinants of Contraceptive Failure, Switching, and Discontinuation: An Analysis of DHS Contraceptive Histories. Calverton, MD: Demographic Health Surveys, Macro International, Inc.; 1997.

13. Population Division. Levels and Trends of Contraceptive Use as Assessed in 2002. New York, NY: Department of Economic and Social Affairs, United Nations; 2006.
14. Cleland J, Bernstein S, Ezeh A, Faundes A, Glasier A, Innis J. Family planning: the unfinished agenda. Lancet. 2006;368(9549):1810-1827.

15. Blanc AK, Curtis SL, Croft TN. Monitoring contraceptive continuation: links to fertility outcomes and quality of care. Stud Fam Plann. 2002;33(2):127-140.

16. Dunn OJ, Clark VA. Applied Statistics: Analysis of Variance and Regression. Toronto, ON: John Wiley and Sons; 1974.

17. Stevens J. Applied Multivariate Statistics for the Social Sciences. Mahwah, NJ: Lawrence Erlbaum Associates; 1996.

18. StataCorp: Stata statistical software: Release 12. College Station, TX: StataCorp LP; 2011.

19. Ramstrom KC, Barón AE, Crane LA, Shlay JC. Predictors of contraceptive discontinuation in a sexually transmitted disease clinic population. Perspect Sex Reprod Health. 2002;34(3):146-152.

\section{Publish your work in this journal}

Open Access Journal of Contraception is an international, peerreviewed, open access, online journal, publishing original research, reports, reviews and commentaries on all areas of contraception. In addition to clinical research, demographics and health-related aspects, the journal welcomes new findings in animal and preclinical studies relating to understanding the biological mechanisms and practical development of new contraceptive agents. The manuscript management system is completely online and includes a very quick and fair peer-review system. Visit http://www.dovepress.com/testimonials.php to read real quotes from published authors.

Submit your manuscript here: http://www.dovepress.com/open-access-journal-of-contraception-journal 